\title{
Polycyclic aromatic hydrocarbons in the atmosphere of Data Darbar Chowk of Lahore, Pakistan
}

\author{
I. Kalim ${ }^{1,2 *}$, N. Zahra ${ }^{2}$, M. K. Saeed ${ }^{2}$, R. Gilani ${ }^{1}$, A. Munawar ${ }^{1}$ and M. I. Jalees ${ }^{3}$ \\ ${ }^{1}$ Department of Chemistry, University of Engineering and Technology, Lahore-54890, Pakistan \\ ${ }^{2}$ Food and Biotechnology Research Centre, Pakistan Council of Scientific and Industrial Research Laboratories Complex, \\ Ferozepur Road, Lahore-54600, Pakistan \\ ${ }^{3}$ Institute of Environmental Engineering \& Research, University of Engineering and Technology, Lahore, Pakistan
}

Received: 25 July 2019

Revised: 31 July 2019

Accepted: 11 November

DOI: https://doi.org/10.3329/bjsir.v55i2.47635

\begin{abstract}
PAHs (polycyclic aromatic hydrocarbons) in atmosphere are amongst the hazardous identified organic pollutants. The present study was conducted on the determination of PAHs concentrations in the air of Data Darbar Chowk, Lahore, Pakistan. The particulate matters in the atmosphere were collected using high volume samplers. Average Total Particulate Matter (mg) of $\mathrm{PM}_{2.5}$ was 20.96 and $\mathrm{PM}_{10}$ was 188.7. The concentration of $\mathrm{PM}_{2.5}$ was $698.81 \mathrm{ngm}^{-3} / \mathrm{hr}$ and $16771 \mathrm{ngm}^{-3} /$ day while concentration of $\mathrm{PM}_{10}$ was $6290 \mathrm{ngm}^{-3} / \mathrm{hr}$ and $150960 \mathrm{ngm}^{-3} /$ day. Quantification of different PAHs and related compounds was done by using Gas Chromatography. The mean total quantity of PAH in air was $955.588 \mathrm{ngm}^{-3}$. The mean concentration of dibenzo $(\mathrm{a}, \mathrm{h})$ anthracene was highest i.e. 161.33 $\mathrm{ngm}^{-3}$ with $13.94 \mathrm{ngm}^{-3}$ Minimum and $308.72 \mathrm{ngm}^{-3}$ Maximum, concentrations. PAHs concentration was found to be very high in current research. There should be proper control through air management system to tackle with harmfulness of health hazardous organic pollutants.
\end{abstract}

Keywords: Polycyclic aromatic hydrocarbon; Organic pollutant; Suspended particulate matter gas chromatography

\section{Introduction}

Polycyclic aromatic hydrocarbons (PAHs), these species of chemical can be regarded as the organic compounds containing only carbon and hydrogen which are comprised of multiple aromatic rings. These PAHs can be added to atmosphere easily by burning or cricking products of fossil fuels. Their major source in atmosphere is vehicle exhaust due to improper and or incomplete combustion of fossil fuel, these are also added to atmosphere as gases and particulates matter coming out of the power plants (Fang et al., 2004).

Some of the PAHs that are being investigated in this study are the most persistent carcinogenic and teratogenic compounds that have been declared lethal as they have been stated by the IARC and USEPA. A number of these toxicants are in Pakistani atmosphere especially in the area of study that is Lahore. Among all PAHs 16 compounds were targeted to study are in the category of the most dangerous persistent organic pollutant (POP) (Vineis and Kirsti, 2005). Concentrations of polycyclic aromatic hydrocarbons (PAHs) were quantified in air and precipitation at a background site in central Europe. The PAH concentrations in air and rainwater ranged from 0.7 to $327.9 \mathrm{ngm}^{-3}$ (Shahpoury et al., 2015).

Polycyclic aromatic compounds of two or more benzenoid groups in their structure and various functional groups which may contain several elements. An important group of polycyclic aromatic compounds are the polycyclic aromatic hydrocarbons (PAHs) which have two or more fused benzonoid rings and no elements other than carbon and hydrogen (Henner et al., 1997). PAHs may be eliminated or transformed to even more toxic compounds by chemical reactions such as sulfonation, nitration or photooxidation. For instance, in

\footnotetext{
*Corresponding author e-mail: ikalim@hotmail.com
} 
some conditions, traces of nitric acid can transform some PAHs into nitro-PAHs (Marce and Borrull, 2000).

There is no accessible data on PAHs presence in atmosphere of Data Darbar Chowk Lahore, Pakistan, so the main purpose of the present research was to get the important introductory information concerning the concentration of PAHs present in the total suspended particulate matters (SPM) in the air of research area.

\section{Materials and methods}

The air samples were collected from Data Darbar Chowk, Lahore which is one of the busiest roads of Lahore with respect to traffic in peripheral areas (Figure 1).
Soxhlet apparatus for $24 \mathrm{~h}$. The extract having soluble organic matter was concentrated and dried under nitrogen gas condition which was further fractionated by chromatographic method (Kalim et al., 2015).

SPM was further fractionated into alkanes, aromatics, nitrogen, oxygen and sulphur containing compounds by column chromatography using silica gel. Alumina was used to fractionate aromatic by column chromatography (Kalim et al., 2016). One-way analysis of variance (ANOVA) was applied by using SPSS 17.0 (IBM SPSS Statistics 19).

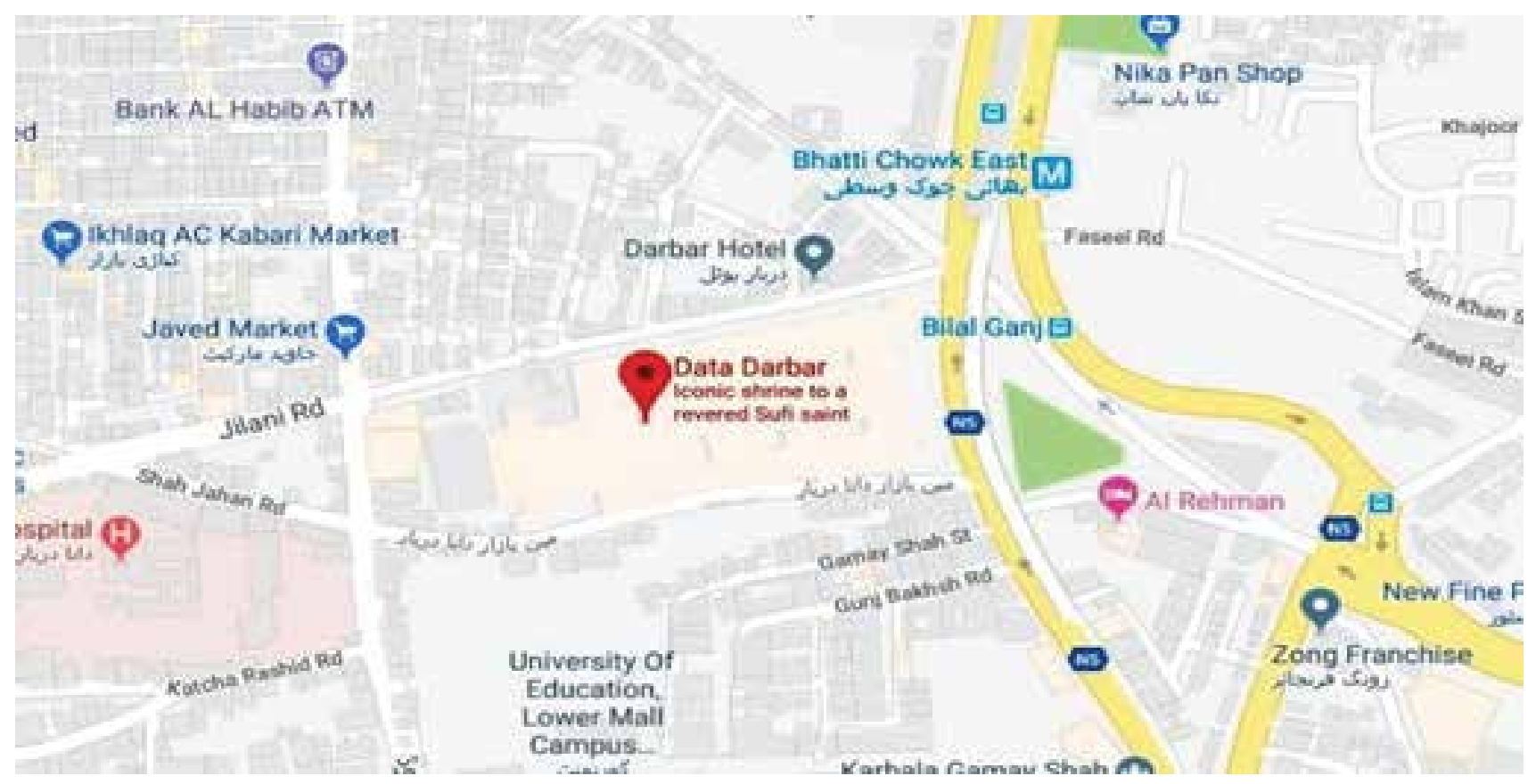

Fig. 1. Location of sampling area

The samples were collected on three different times i.e., first portion was from school and office timings, the second portion was from schools off time while the third portion was from the offices off-time, all these tenures contain the maximum utilization of vehicles and electricity generators that enhance the exhaust containing more than $90 \%$ of the PAHs described in present research.

Analytical grade solvents like methanol, dichloromethane, cyclohexane, chloroform and ethanol (Merck; B.P.) were used in study. In column chromatography of PAH mixture, silica gel of 100 mesh (Merck) was used. Silica gel was activated at $105^{\circ} \mathrm{C}$ for $24 \mathrm{~h}$ before use. The weighed glass fiber filters were used for the extraction using cyclohexane in

\section{Results and discussion}

The present research involves the analysis of health hazardous organic pollutants PAHs in ambient air of Data Darbar Chowk, Lahore. Daily average concentration of total particulate matter was calculated in the three samples collected at morning, afternoon and evening on the same day of selected area. 12 samples were collected and quantified for 22 PAHs. PAHs were absorbed on PM and the higher the particulate matter, the higher will be the concentration of PAHs in the air samples. The results of total particulate matter $\left(\mathrm{PM}_{2.5}\right.$ and $\left.\mathrm{PM}_{10}\right)$ concentrations are given in Table I. 
Particulate matter presence in atmosphere is challenging for the global environment. Solar radiation penetration to the earth's surface is said to be reduced by Aerosol particles in air. They have also a close correlation with increased respiratory issues in Pakistan.
The concentrations of 22 PAHs analyzed in the particulate fractions of air samples of Data Darbar Chowk area of Lahore are given in Figure 2 and Table II as minimum, maximum and mean.

Table I. Concentration of total particulate matter from the Data Darbar Chowk, Lahore in the $\mathrm{PM}_{2.5}$ and $\mathrm{PM}_{10}$ fractions of air

\begin{tabular}{cccc}
\hline Particulate Matter & Average TPM (mg) & \multicolumn{2}{c}{ Concentration } \\
\cline { 3 - 4 } & & ngm $^{-3} / \mathrm{hr}^{-3} / \mathrm{day}^{-1}$ & 16771 \\
\hline $\mathrm{PM}_{2.5}$ & 20.96 & 698.81 & 150960 \\
\hline $\mathrm{PM}_{10}$ & 188.70 & 6290 & \\
\hline
\end{tabular}

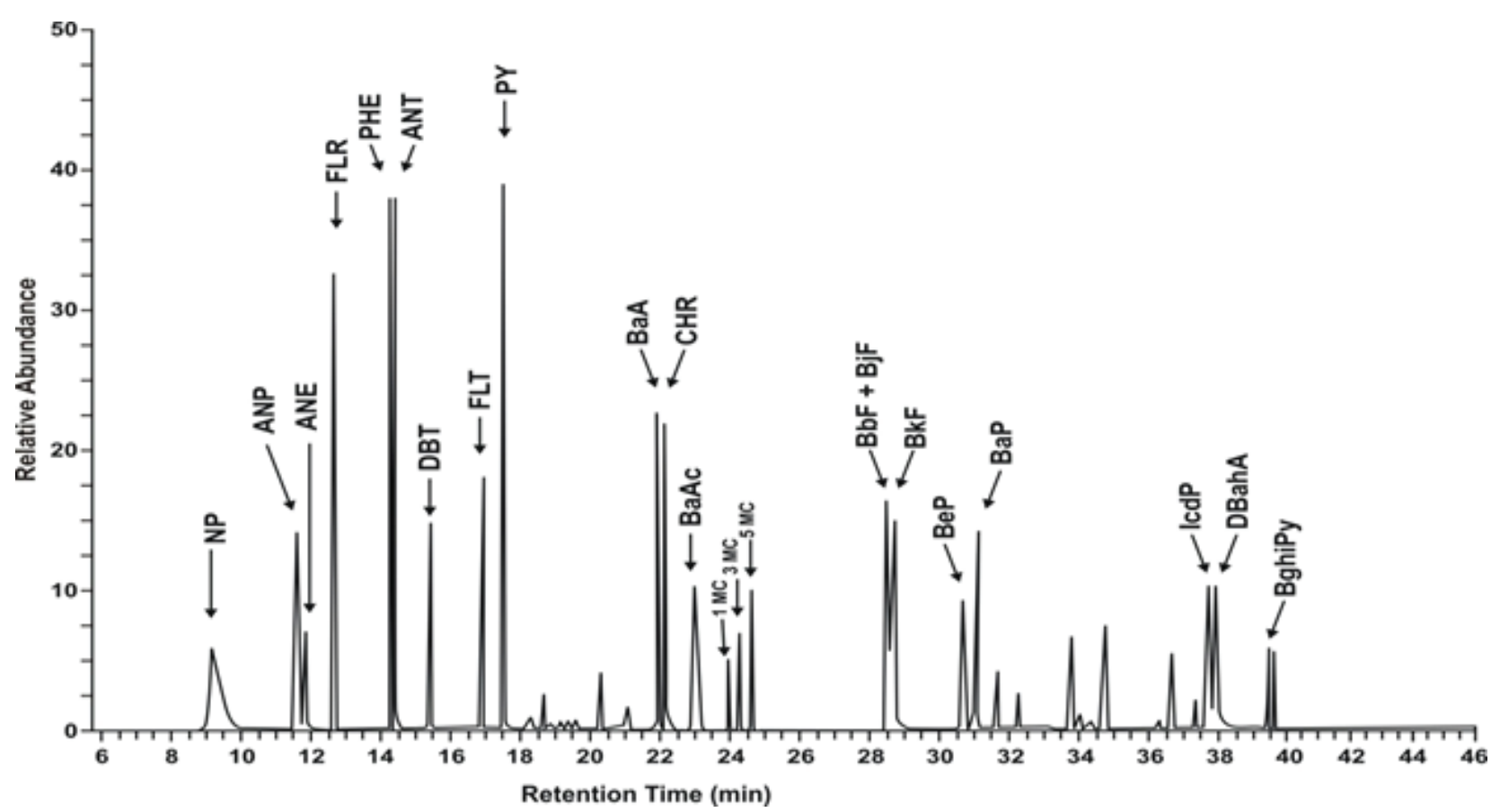

$\mathrm{NP}=$ Naphthalene, ANP $=$ Acenephthylene, ANE $=$ Acenaphthene, FLR $=$ Flourene, $\mathrm{PHE}=\mathrm{Phenathrene}, \mathrm{ANT}=$ Anthracene, $\mathrm{FLT}=$ Fluoranthene, $\mathrm{PY}=$ Pyrene, $\mathrm{BaA}=\mathrm{Benzo}(\mathrm{a})$ Anthracene, $\mathrm{CHR}=\mathrm{Chrysene}, \mathrm{BbF}=\mathrm{Benzo}(\mathrm{b})$ Fluoranthene, $\quad \mathrm{BkF}=\operatorname{Benzo}(\mathrm{k})$ Fluoranthene, $\mathrm{BaP}=\mathrm{Benzo}(\mathrm{a})$ Pyrene, $\mathrm{IcdP}=\operatorname{Indeno}(1,2,3-\mathrm{c}, \mathrm{d}) \mathrm{Pyrene}, \mathrm{DBahA}=$ Dibenzo(a,h)Anthracene, BghiPY = Benzo(ghi)Perylene, DBT = Dibenzothiophene, BaAc = Benz(a)Acridine, 1MC $=1$ Methyl Chrysene, $3 \mathrm{MC}=3$ Methyl Chrysene, $5 \mathrm{MC}=5$ Methyl Chrysene, BeP $=$ Benzo(e)Pyrene.

Fig. 2. Chromatogram of the PAHs and related compounds investigated at Data Darbar Chowk, Lahore, Pakistan 
Table II. Concentration of PAHs and related compounds at Data Darbar Chowk, Lahore, Pakistan

\begin{tabular}{|c|c|c|c|c|}
\hline Sr. No. & PAHs and related compounds & $\operatorname{Min} .\left(\mu \mathrm{gm}^{-3}\right)$ & $\operatorname{Max} .\left(\mu \mathrm{gm}^{-3}\right)$ & Mean $\left(\mu \mathrm{gm}^{-3}\right)$ \\
\hline 1 & Naphthalene & 7.82 & 33.66 & 20.91 \\
\hline 2 & Acenephthylene & 13.26 & 24.48 & 16.32 \\
\hline 3 & Acenaphthene & 0.0017 & 12.24 & 10.268 \\
\hline 4 & Phenathrene & 15.98 & 185.3 & 56.1 \\
\hline 5 & Fluorine & 6.12 & 180.88 & 22.78 \\
\hline 6 & Anthracene & 4.76 & 27.2 & 15.98 \\
\hline 7 & Fluoranthene & 10.54 & 145.52 & 25.33 \\
\hline 8 & Pyrene & 3.74 & 65.28 & 34.51 \\
\hline 9 & Benzo(a)Anthracene & 53.04 & 173.74 & 113.39 \\
\hline 10 & Chrysene & 19.38 & 53.38 & 36.38 \\
\hline 11 & Benzo(b)Fluoranthene & 1.7 & 213.86 & 107.78 \\
\hline 12 & Benzo(k)Fluoranthene & 0.34 & 100.3 & 50.32 \\
\hline 13 & Benzo(a)Pyrene & 0.68 & 162.18 & 81.43 \\
\hline 14 & Dibenzo(a,h)Anthracene & 13.94 & 308.72 & 161.33 \\
\hline 15 & Indeno(1,2,3-c,d)Pyrene & 0.0034 & 41.82 & 20.91 \\
\hline 16 & Benzo(ghi)Perylene & 21.08 & 123.42 & 72.25 \\
\hline 17 & Dibenzothiophene & 2.7 & 38.1 & 19.3 \\
\hline 18 & Benz(a)Acridine & 3.1 & 42.7 & 24.4 \\
\hline 19 & 1Methyl Chrysene & 1.0 & 40.3 & 17.2 \\
\hline 20 & 3Methyl Chrysene & 0.4 & 29.1 & 14.7 \\
\hline 21 & 5Methyl Chrysene & 0.4 & 35.2 & 13.8 \\
\hline \multirow[t]{2}{*}{22} & Benzo(e)Pyrene & 9.1 & 84.6 & 20.2 \\
\hline & Total & 189.0851 & 2121.98 & 955.588 \\
\hline
\end{tabular}

In current study the dibenzo(a,h) anthracene concentration was found to be highest among all PAHs i.e. $161.33 \mathrm{ngm}^{-3}$ with $13.94 \mathrm{ngm}^{-3}$ and $308.72 \mathrm{ngm}^{-3}$, mean, minimum and maximum concentration correspondingly. The present research work explains the complete and detailed data of the ambient air quality of one of busiest area of Lahore with respect to the investigation of total particulate matter and PAHs with complete figures and facts supported by analyses of one of the most sensitive analytical techniques. Such details of data have not been discussed earlier about the ambient air quality of Data Darbar, Lahore.
Different studies have shown that photolysis of anthracene, benzo[a]anthracene and benzo[a]pyrene takes place in the environment at tremendously faster rates. Aerosols of $\mathrm{PM}_{2.5}$ are the mainly photoreactive components (Stone et al., 2010).

A very small amount of data regarding PAHs carcinogenity has been obtained from under developed countries. In India one of the study depicts that the PAHs concentration in air of industrial areas i.e. 90.000 to $195.000 \mathrm{ngm}^{-3}$ was double than the inhabited areas having concentration of PAHs about 23.000 to $66.000 \mathrm{ngm}^{-3}$ (Pandit et al., 1996). 
The higher amounts of PAHs and related compounds especially benzo[e] pyrene in air is increasing day by day due to the uncontrolled burning of industrial and agricultural wastes in huge amounts. This situation is a big threat to health of people living in rural as well as in urban areas (Zhang and Tao, 2009). In heavily traffic areas, the workers exposed to PAHs and related compounds are facing severe health issues like lung, bladder skin and gastrointestinal cancers.

In a similar study, the concentration of 16 PAHs in the particulate matter of air samples of Kot Lakhpat area of Lahore was noted. The mean concentration of dibenzo $(\mathrm{a}, \mathrm{h})$ anthracene was found to be highest among all PAHs i.e., 123.370 ngm $^{-3}$ (Kalim et al., 2018).

Figure 3 depicts the nastiest situation of PAHs presence in the air of Data Darbar area of Lahore city. PAHs attached with dust particles in the environment may cause diverse diseases in humans who are exposed to PAHs particles. There must be suitable plans to assess PAHs toxicity levels. Proper environmental manage procedures should be adapted to check PAHs concentration in air, food and water in order to secure human health from severe health circumstances.

\section{Conclusion}

From the present study, it was concluded that the area of Data Darbar has enormous and hazardous concentration levels of harmful PAH organic particles in the air. The Data Darbar area of Lahore has been incalculably polluted with PAHs components. The particulate pollution is affecting badly the entire environment of selected area. The exhaust from automobiles contains a huge amount of PAHs which is increasing at infinitum. Seasonal extremity is also due to this heavy air pollution of inorganic and organic pollutants. The issue regarding road traffic pollution must be handled at precedence. The alarming situation of increased PAH's level in air of Lahore has now a matter of serious concern as it is badly affecting the health of home inhabitants. The health hazards pretended by PAH exposure should be controlled by proper and effective air quality management system.

\section{References}

Fang GC, Chang CN, Wu YS, Fu PPC, Yang IL and Chen M $\mathrm{H}$ (2004), Characterization, identification of ambient air and road dust polycyclic aromatic hydrocarbons in central Taiwan, Taichung. Science of the Total Environment 327(1-3): 135-146. DOI: 10.1016/j. scitotenv.2003.10.016

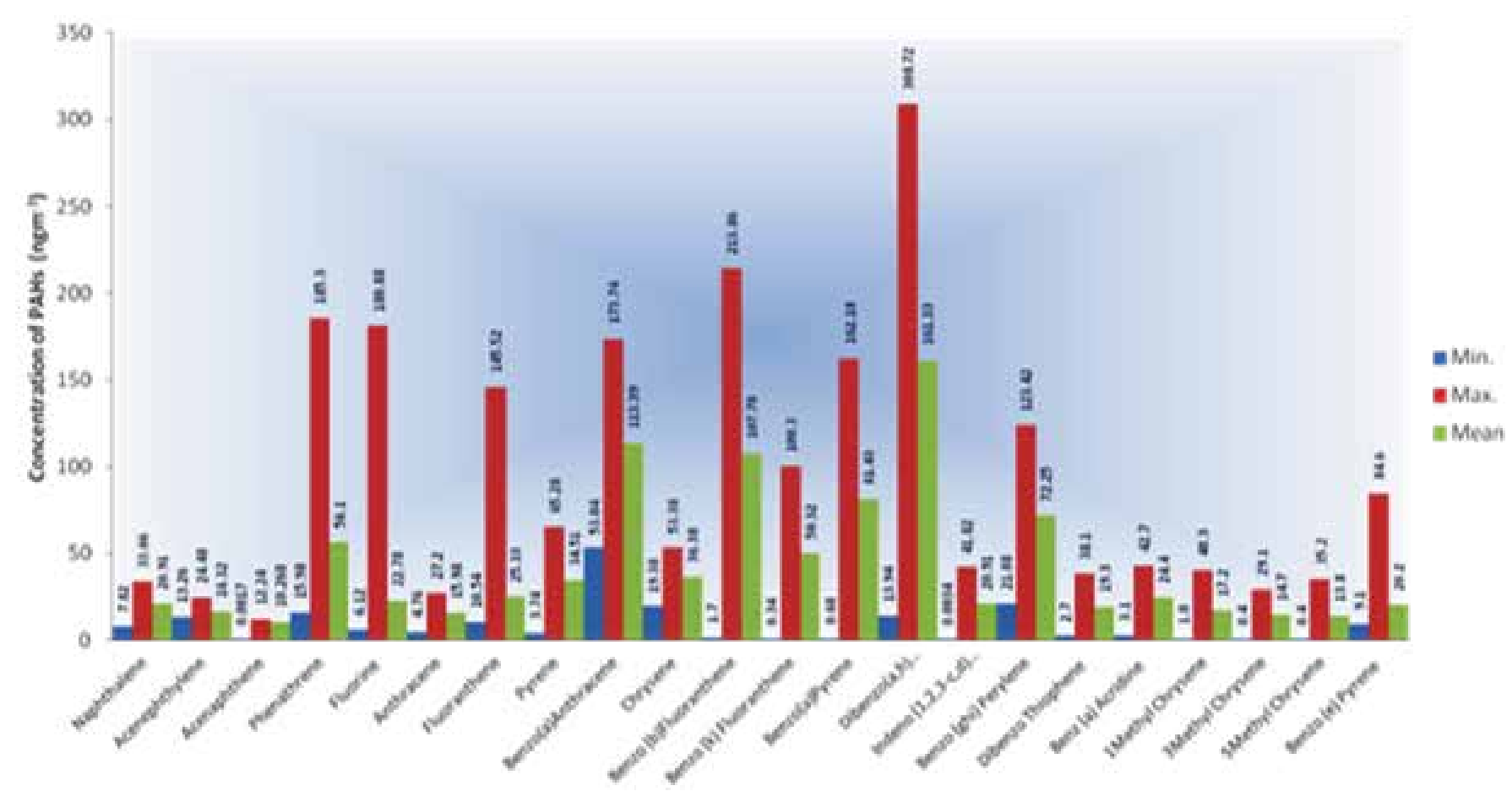

Fig. 3. Concentration of investigated PAHs and related compounds at Data Darbar Chowk, Lahore, Pakistan 
Henner P, Schiavon M, Morel JL and Lichtfouse E (1997), Polycyclic aromatic hydrocarbon (PAH) occurence and remediation methods, Analysis Magazine 25: M56-M59.

Kalim I, Zahra N, Nisa A, Hina S and Fazeelat T (2015), Determination of Polycyclic Aromatic Hydrocarbons in Atmosphere of the City of Lahore, Pakistan, Research Journal of Chemical Sciences 5: 1-6.

Kalim I, Zahra N and Fazeelat T (2016), Estimation of polycyclic aromatic hydrocarbons (PAH's) Present in the atmosphere of urbanized region Badami Bagh in Lahore, Pakistan, Pakistan Journal of Science 68: 139-145.

Kalim I, Zahra N, Gilani R and Liviu M (2018), Assessment of Polycyclic Aromatic Hydrocarbons (PAHs) Present in the Atmosphere of Kot Lakhpat Industrial Estate of Lahore, Pakistan, Pakistan Journal of Scientific and Industrial Research 61A(3): 132-137.

Marcè RM and Borrull F (2000), Solid Phase extraction of polycyclic aromatic compounds, Journal of Chromatography A. 885: 273-290. DOI: 10.1016/S0021-9673(00)00428-3

Pandit GG, Sharma S, Mohan RAM and Krishnamoorthy T M (1996), Chromatographic methods for the estimation of polycyclic aromatic hydrocarbons in atmospheric particulates $5^{\text {th }}$ National Symposium on Environment, Calcutta, India, 8 Feb. 28-1 March, pp 133-136.

Shahpoury P, Lammel G, Holubová Š, mejkalová A, Klánová J, Přibylová P and Váňa M (2015), Polycyclic aromatic hydrocarbons, polychlorinated biphenyls, and chlorinated pesticides in background air in central Europe-investigating parameters affecting wet scavenging of polycyclic aromatic hydrocarbons. Atmospheric Chemistry and Physics 15(4): 1795-1805.

Stone E, Schauer J, Quraishi TA and Mahmood A (2010), Chemical characterization and source apportionment of fine and coarse particulate matter in Lahore, Pakistan. Atmospheric Environment 44: 1062-1070. DOI: 10.1016/j.atmosenv.2009.12.015

Vineis P and Kirsti H (2005), Air pollution and cancer: biomarker studies in human populations, Carcinogenesis 26(11): 1846-1855. DOI: 10.1093/carcin/bgi216

Zhang Y and Tao S (2009), Global atmospheric emission inventory of polycyclic aromatic hydrocarbons (PAHs) for 2004. Atmospheric Environment 43(4): 812-819. DOI: 10.1016/j.atmosenv.2008.10.050 